\title{
Da Retomada à Escolarização ao Acesso e Permanência na Universidade: O PAIETS Como Possibilidade de Transformação Social
}

\author{
From returning to school to accessing and attending University: The PAIETS as \\ Possibility of Social Transformation
}

\author{
Roberta Avila Pereira ${ }^{1}$, Lisiane Costa Claro $^{2}$, Vilmar Alves Pereira ${ }^{3}$ \\ 1 Acadêmica. Universidade Federal do Rio Grande (FURC), Brasil. E-mail: brunaroberta83@hotmail.com \\ 2 Doutoranda. Universidade Federal do Rio Grande (FURC), Brasil. E-mail: Iisianecostaclaro@hotmail.com \\ 3 Professor. Universidade Federal do Rio Grande (FURC), Brasil. E-mail: vilmar1972@gmail.com
}

Recebido em: 01/04/2015 | Aprovado em: 23/09/2015

DOI: 10.12957/interag.2016.15923

\begin{abstract}
Resumo
O presente texto apresenta as experiências do Programa de Auxílio ao Ingresso aos Ensinos Técnico e Superior - PAIETS da Universidade Federal do Rio Grande - FURG na luta pela retomada da educação básica, acesso e permanência da camada popular no Ensino Superior público e de qualidade, além da busca pela educação permanente a partir de uma formação no horizonte da educação popular. Diante disso, as ações do PAIETS se materializam através dos cursos pré-universitários populares, localizados nos bairros populares da cidade de Rio Grande/RS, São José do Norte/RS, Capão do Leão/RS e Santo Antônio da Patrulha/RS; do subprograma PAIETS Indígena e Quilombola; da retomada das comunidades tradicionais da Educação Básica no Projeto Educação para Pescadores e do projeto de formação Permanente Olhares Sul-Rio-Grandense na formação de Jovens e Adultos. Neste sentido, as práticas desenvolvidas nos contextos de atuação do PAIETS objetivam potencializar ações educativas que tenham em seu horizonte a Educação Popular como uma escolha política, uma vez que entendemos que a prática educativa é uma das formas de se lutar a favor da emancipação humana. Os princípios orientadores das práticas do programa apostam numa formação crítica e política, na possibilidade do 'ser mais'. Portanto, as quatro frentes de trabalho do PAIETS assumem o objetivo da emancipação coletiva, defendendo o espaço do Ensino Superior como um direito e uma possibilidade das classes populares.
\end{abstract}

Palavras-chave: Educação Popular. Acesso. Permanência. Formação.

\begin{abstract}
This paper presents the experiences of the Aid Program to Join the Technical and Superior Education (PAIETS) at the Federal University of Rio Grande (FURG), in the campaign for the recovery of basic education, access and attendance of the popular classes in state and quality in higher education, in addition to the pursuit of permanent learning from the point of view of popular education. Therefore, the PAIETS actions materialize through popular pre-university courses, located in the popular neighborhoods of Rio Grande $R S$, São José do Norte - RS, Capão do Leão - RS, and Santo Antônio da Patrulha - RS; from the PAIETS Natives and Quilombola subprogram; the recovery of traditional communities of Basic Education, in the Education for Fishermen project, and Sul-Rio-Grande Looks project for the training of Adult and Young students. In this sense, the practices developed in the contexts of activity of PAIETS aim at enhancing educational activities that reckon Popular Education as a political choice, since we understand that educational practice is one way to fight for human emancipation. The guiding principles of the program practices are committed to critical and political training - the possibility of 'being more'. Therefore, the four work fronts of PAIETS assume the goal of collective emancipation, holding higher education as a right and a possibility for the popular classes.
\end{abstract}

Keywords: Popular Education. Access. Permanence. Training. 
Área temática: Educação.

Linha de extensão: Educação Popular.

\section{Primeiras Palavras}

O Programa de Auxílio ao Ingresso aos Ensinos Técnico e Superior - PAIETS da Universidade Federal do Rio Grande - FURG é uma proposta na área da extensão acadêmica que atua em quatro frentes: 1) No acesso ao Ensino Superior junto aos PréUniversitários Populares. 2) Na retomada à educação básica junto a Jovens e Adultos das comunidades tradicionais de pesca artesanal. 3) $\mathrm{Na}$ permanência de sujeitos oriundos de comunidades quilombolas e indígenas no espaço acadêmico. 4) Na formação docente da rede pública.

Neste sentido, como a primeira frente de atuação, o PAIETS agrupa cursos préuniversitários populares visando, entre outros aspectos, o acesso para o ingresso nos ensinos superior e técnico e pretende também proporcionar à comunidade a possibilidade de estudo numa universidade pública e gratuita com qualidade e permanência. Desse modo, aproximadamente 180 acadêmicos de graduação e pósgraduação e colaboradores já formados, comprometem-se em desenvolver práticas educativas de diferentes campos do saber, orientadas pelos princípios que embasam a Educação Popular, no auxílio ao preparo para os processos seletivos de ingresso no ensino técnico e superior.

O referido programa teve início em 2007, contemplado no edital PROEXT 06/2007, e, em 2008, teve adesão de novos docentes e acadêmicos-educadores, desenvolvendo novas ações e oportunizando a criação de novos cursos populares. No ano de 2009 , o trabalho foi ampliado para 500 estudantes. Atualmente, encontram-se vinculados ao programa 06 cursos pré-universitários populares na cidade do Rio Grande/RS, que estão em desenvolvimento nas vilas e bairros populares da cidade, 01 curso préuniversitário popular em São José do Norte/RS, o1 curso pré-universitário popular em 
Capão do Leão/RS, 01 curso pré-universitário popular em Santo Antônio da Patrulha/RS.

Além disso, temos o Projeto Educação para Pescadores, em nível fundamental e médio na comunidade da Capilha (Rio Grande/RS), que busca a retomada da Educação Básica nas comunidades tradicionais de pesca artesanal e, ainda, o projeto PAIETS Indígena e Quilombola, que realiza um trabalho de acolhida e acompanhamentos aos estudantes indígenas e quilombolas ingressantes na Universidade mediante processo seletivo específico. Mais recentemente, a partir de 2013, o PAIETS também atua em parceria com a $18^{a}$ Coordenadoria Regional de Educação/RS e com a Secretaria Municipal de Educação da cidade do Rio Grande/RS na formação de professores da EJA na cidade.

\section{Para Iniciar a Conversa...}

Consideramos relevante em um primeiro momento situar o campo de vivências no que concerne a questões epistemológicas. Neste sentido, buscamos aqui traçar algumas reflexões sobre o entendimento de Educação Popular, alicerçado principalmente em Paulo Freire, compreendendo-a como uma possibilidade de resistência frente a uma lógica que distancia a camada popular de ocupar os espaços da sociedade.

Neste sentido, na atual estrutura de nossa sociedade, são notórias as contradições da lógica capitalista existentes no processo educativo, principalmente no que concerne a luta cotidiana da camada popular para ter acesso e permanecer na universidade, dando continuidade aos seus estudos. Podemos afirmar, a partir de Antunes ${ }^{1}$, que a lógica do capital promove a necessidade dos sujeitos ingressarem cedo no mercado de trabalho e, desse modo, é impossibilitada a continuidade de escolarização de muitos sujeitos, acarretando a dificuldade de que, ao vivenciarem as demandas do trabalho, deixam para trás o sonho de continuar seus estudos.

Nesse contexto de desigualdade social que permeia a educação, é possível entender que a classe opressora foi quem induziu muitos sujeitos das classes populares a permanecerem fora dos processos educativos formais, preparando o sujeito para o mundo do trabalho ${ }^{2} \mathrm{e}$, consequentemente, não tendo a oportunidade de acesso $\mathrm{e}$ permanência nas instituições de ensino, a não ser quando tratar-se de instruções 
necessárias às demandas do mercado, o qual vem ocasionando a subproletarização da massa trabalhadora, como salienta Antunes ${ }^{1}$.

Ponderamos que as práticas desenvolvidas nos contextos de atuação do PAIETS, alicerçadas na Educação Popular, com fundamentos teóricos de diversos autores, estão direcionadas para a superação destas desigualdades na busca pela construção de uma nova organização social. Nesse sentido, convém lembrar o papel assumido pela educação popular, na qual, conforme Freires, o educador é o mediador na sala de aula através de partilhas de conhecimentos. Na perspectiva de Freires, "a educação autêntica, repitamos, não se faz de $\mathrm{A}$ para $\mathrm{B}$ ou de $\mathrm{A}$ sobre $\mathrm{B}$, mas de $\mathrm{A} \operatorname{com} \mathrm{B}$, mediatizados pelo mundo. Mundo que impressiona e desafia a uns e a outros, originando visões ou pontos de vista sobre ele”.

Nos contextos populares vinculados ao programa, nossas ações são voltadas para o coletivo, possibilitando a intervenção e participação dos educandos e educadores nas práticas. Para tanto, nossas ações são orientadas na perspectiva da Educação Popular. Esta educação, voltada para/com o povo, permite que tenhamos uma reflexão acerca da realidade em que estamos inseridos, permitindo também que, em diferentes contextos, o desenvolvimento da aprendizagem seja partilhado no coletivo, através da escuta. Nessa perspectiva, Brandão ${ }^{4}$ compreende e sugere que "A Educação Popular não é uma atividade pedagógica para, mas um trabalho coletivo em si mesmo”.

Além disso, ponderamos que a prática pedagógica precisa estar voltada para a criticidade dos educandos e educandas, através de formação continuada e permanente. Precisamos estabelecer uma relação de confiabilidade que aponta para uma nova ontologia, criando possibilidades dos sujeitos de ser mais.

Ao buscarmos a libertação com o coletivo, rompemos com as camadas opressoras numa interação recíproca entre os sujeitos. A educação é um meio de se lutar contra as classes opressoras; através desse instrumento educativo poderemos ter a transformação social que almejamos e a hegemonia das classes sociais. 


\section{Contextos do PAIETS e as possibilidades de transformação}

Diante disso, os cursos pré-universitários populares orientam suas práticas no horizonte da Educação Popular, a partir de autores como Paulo Freire, Carlos Brandão, entre outros. Para tanto, as ações que são desenvolvidas visam formação crítica e política dos sujeitos envolvidos no processo. Esta perspectiva permite que o desenvolvimento da aprendizagem seja partilhado no coletivo, através da escuta. Para Brandão ${ }^{4}$,

\footnotetext{
Educação popular é aquela que, ao longo da História da própria Educação, insiste em fazer a seu respeito, e também sobre o sentido social do ato de educar, as perguntas mais radicais e as mais difíceis, para se obter, se isso é possível, as respostas mais concretamente utópicas.
}

Assim, consideramos que a Educação Popular não se conforma em aceitar respostas fixistas que tendem a perpetuar desigualdades. Com isso, os sujeitos envolvidos nesse processo questionador tornam-se atores sociais, que fomentam mudanças e rupturas por meio de sua curiosidade epistemológica - exercício este que leva à consciência crítica.

Com relação à retomada da escolarização nos espaços tradicionais de pesca artesanal do município, o PAIETS em parceria com o Projeto Educação para Pescadores ainda conta com o apoio de diversas instituições: por meio da Capitania dos Portos, Secretarias Municipais e Secretaria Estadual de Educação. Essa parceria, por um lado, demonstra a tentativa de suprir a falha do Estado Nacional que, historicamente, negligenciou a escolarização no contexto de pesca artesanal da Ilha dos Marinheiros, na Ilha da Torotama e Vila da Capilha, ao não contemplar as necessidades destas comunidades com relação ao ensino formal básico completo.

Atualmente, o espaço assume o objetivo de "oportunizar aos pescadores e seus familiares a continuidade de seus estudos, de forma a valorizar seus saberes e vivências, possibilitando a conclusão do Ensino Fundamental e Ensino Médio". ${ }^{5}$ Assim, é assumida a visão de que é necessário construir os saberes a partir das experiências de vida dos educandos. 
No que concerne à permanência dos estudantes de comunidades tradicionais Quilombos e Aldeias Indígenas - as ações do programa dão-se no sentido de acolhida e acompanhamento destes na universidade. Uma vez que estes sujeitos se inserem no espaço do Ensino Superior, através do processo seletivo específico, que é uma ação afirmativa da FURG, o Programa busca realizar um acompanhamento desses estudantes por meio de oficinas. Esses encontros emergem a partir da demanda em relação aos desafios enfrentados pelos educandos ao adentrar a Universidade, trabalhando a partir das suas necessidades, para uma melhoria no seu desempenho enquanto graduando.

Nessa perspectiva, são elaboradas de forma conjunta com os estudantes, oficinas de Produção Textual e Estatística. A primeira tem como preocupação o âmbito da linguagem e escrita presentes na academia, mas acontecem a partir de textos condizentes com a realidade dos sujeitos que constituem a comunidade. Portanto, esse espaço nasce da compreensão de suas dificuldades na ortografia, busca esclarecer suas dúvidas de coesão e coerência, auxiliando sua escrita e desenvolvimento de trabalhos. Já a oficina de estatística assume o objetivo de esclarecer dúvidas de estudantes, na maioria graduandos de Psicologia, em relação a gráficos estatísticos, muito usados em trabalhos, entre outras exigências, das áreas de atuação desses estudantes.

Por fim, destacamos o espaço de formação permanente com professores de EJA, os quais são realizados mensalmente em círculos de cultura. A metodologia que orienta os encontros com os mais de 200 educadores vinculados ao projeto, divididos em pequenos grupos, é a compreensão que a prática educativa precisa ser repensada e ressignificada através do local onde "os pés pisam”. Entendemos que a constante reflexão acerca do processo de conhecimento leva o sujeito a interrogar suas práticas, identidades e formas de ser a fim de traçar possibilidades de seu porvir; portanto, o desafio colocado

\footnotetext{
[...] reside, neste ponto da reflexão, na capacidade de cada um viver como sujeito de sua formação, em outras palavras, de fazer tomadas de consciência não somente para a reivindicação de ser sujeito, mas para sua realização, por mais difícil e frágil que possa ser. $[\ldots]]^{6}$
} 
Deste modo, ao construirmos espaços de diálogo e de compartilhamento das experiências vivenciadas e na compreensão de que o ato de revisitar a própria trajetória enquanto sujeitos em permanente e constante construção, constitui o elemento fundante do processo (auto) formativo.

\section{Considerações Finais}

Assim, a atuação do PAIETS vem apresentando resultados significativos no que se refere à democratização do acesso e da permanência da camada popular na universidade pública e de qualidade. E, neste sentido, as ações do PAIETS, no que concerne aos pressupostos epistemológicos, apostam na democratização do ingresso e permanência à universidade como direito, entendendo que através da inserção participativa e crítica de sujeitos, que historicamente estão à margem da sociedade, é que alcançaremos a transformação social que almejamos.

Dessa forma, nas práticas desenvolvidas está intrínseca a aposta no ser mais dos educandos enquanto sujeitos que buscam pelas suas lutas cotidianas superar a lógica de um sistema que não acredita nas condições de emancipação do sujeito. A educação é um meio de se lutar contra a lógica opressora. Por meio do instrumento educativo, buscase a transformação social.

Pode-se ressaltar, nesta perspectiva, a importância deste programa para uma sociedade mais justa, a qual reconheça as diferenças no horizonte dialógico, crítico e esperançoso. Durante todos esses anos de atuação, passaram pelos contextos do PAIETS diversos educandos encharcados de sonhos, o que torna possível realizar e afirmar a relevância social que este programa exerce na nossa sociedade.

Com a certeza de que novos olhares para o processo de inclusão dialogam com os preceitos da Educação Popular, acreditamos que a universidade - assim como outros espaços - além de direito de todos, é uma possibilidade que deve ser oportunizada a todos como uma forma de resgate e comprometimento social com os grupos socialmente marginalizados ao longo do tempo. Ousamos trilhar esse caminho, pois acreditamos em uma universidade inclusiva e comprometida com o social. 


\section{Referências}

1. ANTUNES, Ricardo. Adeus ao Trabalho? Ensaio sobre as Metamorfoses e a Centralidade do Mundo do Trabalho. São Paulo: Cortez; Campinas, SP: Editora da Universidade Estadual de Campinas, 2002.

2. FRIGOTTO,Gaudencio (org.). Educação e crise do trabalho: perspectivas de final de século. Rio de Janeiro, Vozes, 1998.

3. FREIRE, Paulo. Pedagogia do Oprimido. $17^{\mathrm{a}}$ Ed. Rio de Janeiro: Paz e Terra, 1987.

4. BRANDÃO, Carlos R. O que é Educação Popular? São Paulo: Coleção 318 , Primeiros Passos, Brasiliense. 2006.

5. RIO GRANDE DO SUL, Projeto Político Pedagógico do Projeto Educação para Pescadores. Rio Grande/RS, 2012. 4 p.

6. JOSSO, Marie-Christine. Caminhar para si. Trad. Albino Pozzer; Coord. Maria Helena Menna Barreto Abrahão. Porto Alegre; EDIPUCRS, 2010. 